\title{
Efeitos de surfactantes na atividade catalítica da lipase de Botryosphaeria ribis EC-01
}

\author{
$\underline{\text { Márcio de Barros }}^{1}$, Maria Inês Rezende ${ }^{1}$, Milena Martins Andrade ${ }^{2}$, e \\ Aneli M. Barbosa ${ }^{3}$ \\ ${ }^{1}$ Universidade Estadual de Londrina - UEL - Departamento de Bioquímica e Biotecnologia \\ Caixa Postal 10011 - 86057-970 Londrina - PR E-mail:marciodebarros@hotmail.com \\ Universidade Tecnológica Federal do Paraná - UTFPR - Coordenação de Licenciatura em Química \\ 86812-460 - Apucarana - PR. \\ 3Universidade Estadual de Londrina - UEL -Departamento de Química Caixa Postal 10011 - 86057-970 \\ Londrina - PR
}

\begin{abstract}
RESUMO
Lipases são proteínas com atividade catalítica que hidrolisam triacilgliceróis a ácido graxos e glicerol. Devido às suas peculiaridades, estas enzimas são promissoras para aplicação em diversos segmentos da indústria. Dando continuidade à pesquisa sobre a aplicação tecnológica da lipase de Botryosphaeria ribis EC-01, neste trabalho sua atividade foi avaliada em meio reacional contendo diferentes surfactantes com ou sem adição de ín $\mathrm{Ca}^{2+}$, o qual pode ou não ativar a atividade de lipases. Observou-se que a atividade da lipase do B. ribis EC-01 diminuiu na presença dos surfactantes Brometo de cetiltrimetil amônio(CTAB) e Tween 80e manteve cerca de $45 \%$ da atividade em 12,4 mM de SDS. O íon $\mathrm{Ca}^{2+}$ não foi efetivo para manter ou elevar a atividade desta lipase nos surfactantes avaliados.
\end{abstract}

Palavras-chave: lipase, Botryosphaeria ribis EC-01, surfactante, íon cálcio.

\section{INTRODUÇÃO}

As lipases(EC 3.1.1.3; triacilglicerolacil hidrolases) são enzimas que catalisam a hidrólisede triacilgliceróis a ácidos graxos eglicerol na interface entre as fases aquosa e lipídica (Jaeger;Eggert, 2002). Estas enzimas são promissoras para aplicações biotecnológicas por sua versatilidade em realizar reações de hidrólise e síntese, muitas vezes quimio, regio ou enantiosseletivas (Barros et al. 2010). As interações tensoativas de enzimas em soluções aquosas têm sido extensivamente estudadas para aplicações tecnológicas, uma vez que as interações entre proteínas e lipídeos devem ser compatíveis (Mendes et al. 2012). Neste estudo foi avaliado o efeito de três surfactantes (CTAB, Tween 80 e SDS) na atividade da lipase de Botryosphaeria ribis EC-01 com ou sem adição de íons cálcio.

\section{Materiais}

\section{MATERIAL E MÉTODOS}

Dodecil sulfato de sódio (SDS), brometo de cetiltrimetil amônio (CTAB),Tween 80, palmitato de $p$-nitrofenila foram obtidos de Sigma-Aldrich (EUA).

Produção da Lipase pelo micro-organismo Botryosphaeria ribis EC-01

O fungo ascomiceto B. ribis (número de acesso Gen Bank DQ852308) foi mantido em batatadextrose ágar a $4{ }^{\circ} \mathrm{C}$ e transferido para placas de Petri com meio mínimo de Vogel, glicose $1 \%$ 


\section{VSIMBBTEC \\ Londrina 2015}

$(\mathrm{m} / \mathrm{v})$ e ágar $2 \%(\mathrm{~m} / \mathrm{v})$ por 5 dias a $28^{\circ} \mathrm{C}$. Sessenta e quatro esferas de $\sim 0,7 \mathrm{~cm}$ de diâmetro, previamente colonizadas, com $B$. ribis EC-01 foram inoculadas em cada frasco de Erlenmeyer (2 L) contendo $400 \mathrm{~mL}$ de meio de Vogel e $1 \%(\mathrm{v} / \mathrm{v})$ de óleo de soja. Os frascos foram incubados em agitador rotatório a $180 \mathrm{rpm}$ e $28{ }^{\circ} \mathrm{C}$ por 5 dias. Os cultivos foram interrompidos por centrifugação a $1500 \mathrm{xg} / 15 \mathrm{~min}$. a $4^{\circ} \mathrm{C}$. Os sobrenadantes foram filtrados em papel Whatmann $\mathrm{N}^{\circ} 1$ pregueado, em banho de gelo. Os filtrados foram dialisados contra água destilada a $4^{\circ} \mathrm{C}$ por $48 \mathrm{~h}$ com várias trocas de água, e em seguida, tratados com sulfato de amônio, sob agitação lenta e constante, até a saturação de $60 \% 4^{\circ} \mathrm{C}$. A mistura permaneceu por $2 \mathrm{~h}$ a $4^{\circ} \mathrm{C}$ para total precipitação das proteínas. Após esse período, a mistura foi centrifugada $(1000 \mathrm{xg} / 15 \mathrm{~min}$. a $4^{\circ} \mathrm{C}$ ) e o precipitado obtido foi ressuspendido em água destilada, dialisado e então armazenado a $-18^{\circ} \mathrm{C}$, para futuras determinações analíticas.

\section{Determinação da atividade de lipase}

A atividade de lipase foi determinada por espectrofotometria, utilizando-se o palmitato de $p$ Nitrofenila como substrato a pH 8,0 e $55^{\circ} \mathrm{C}$, por 2 minutos, a $410 \mathrm{~nm}$ (Messias et al., 2009). A unidade de atividade de lipase foi definida como a quantidade de $p$-NP, em $\mu$ mol,liberado por minuto, por $\mathrm{mL}$ da solução de enzima.

\section{Efeitos de surfactantes na atividade da enzima}

$\mathrm{O}$ efeito de surfactantes na atividade da lipase de $B$. ribis EC-01 foi avaliado determinando-se a atividade lipolítica da enzima no meio reacional contendo os surfactantes: Brometo decetiltrimetil amônio (CTAB), Tween 80 e Dodecil sulfato de sódio (SDS) com concentrações de 0 a 50 mM sem ou com adição de $\mathrm{Ca}^{2+}$ (1 e $5 \mathrm{mM}$ ).

\section{RESULTADOS E DISCUSSÃO}

As Figuras 1, 2 e 3 demostram o efeito dos surfactantes CTAB, SDS e Tween 80 sem ou com adição do íon $\mathrm{Ca}^{2+}$ na atividade da lipase de $B$. ribis EC-01, respectivamente.Os surfactantes CTAB e Tween 80 apresentaram efeito negativo na atividade catalítica da lipase de $B$. ribis EC01 em pequenas concentrações $(1,5 \mathrm{mM})$. No entanto, pode-se observar que cerca de $45 \%$ da atividade enzimática foi mantida até $12,4 \mathrm{mM}$ de SDS (Figura 2). Segundo Reis et al. (2009), geralmente as lipases apresentam aumento de sua atividade catalítica quando surfactantes neutros (como o Tween 80) e catiônicos (como CTAB) estão presentes, porém na presença de aniônicos (como o SDS), a lipase de B. ribis EC-01 mostrou-se mais ativa. Este indício pode ser importante para futuras aplicações em formulações de detergentes.

A lipase da semente de Pachira aquatica estudada por Polizelli et al. (2008) apresentou aumento de sua atividade catalítica quando na presença de CTAB, mesmo em altas concentrações $(50 \mathrm{mM})$, porém decréscimo da mesma quando na presença de SDS. Para 0 Tween 80 obtiveram resultados semelhantes aos obtidos neste trabalho. Os autores avaliaram também a atividade da enzima nos surfactante juntamente com o $\mathrm{Ca}^{2+}$, onde observaram um efeito negativo da adição do cálcio junto aos surfactantes na atividade lipolítica da enzima. Fato também observado neste trabalho. 


\section{SIMPÓSIO DE BIOQUÍMICA E BIOTECNOLOGIA}

05 a 07 de agosto de 2015, Londrina - PR

\section{VSIMBBTEC}

Londrina 2015

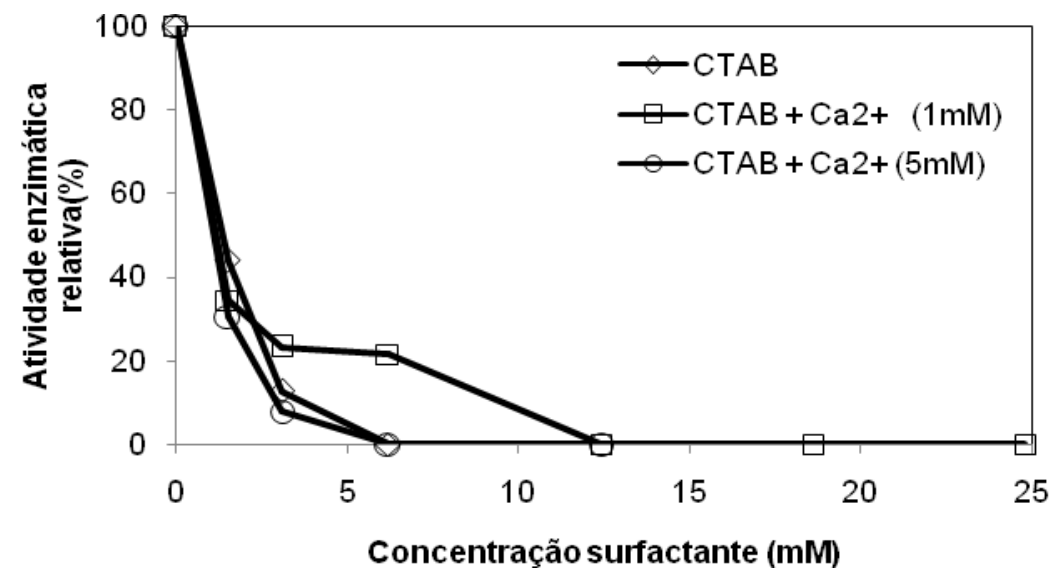

Figura 1: Efeito de diferentes concentrações de CTAB com e sem adição de íons cálcio na atividade catalítica da lipase de Botryosphaeria ribis EC-01. Cada ponto constitui a média de triplicatas \pm SD.

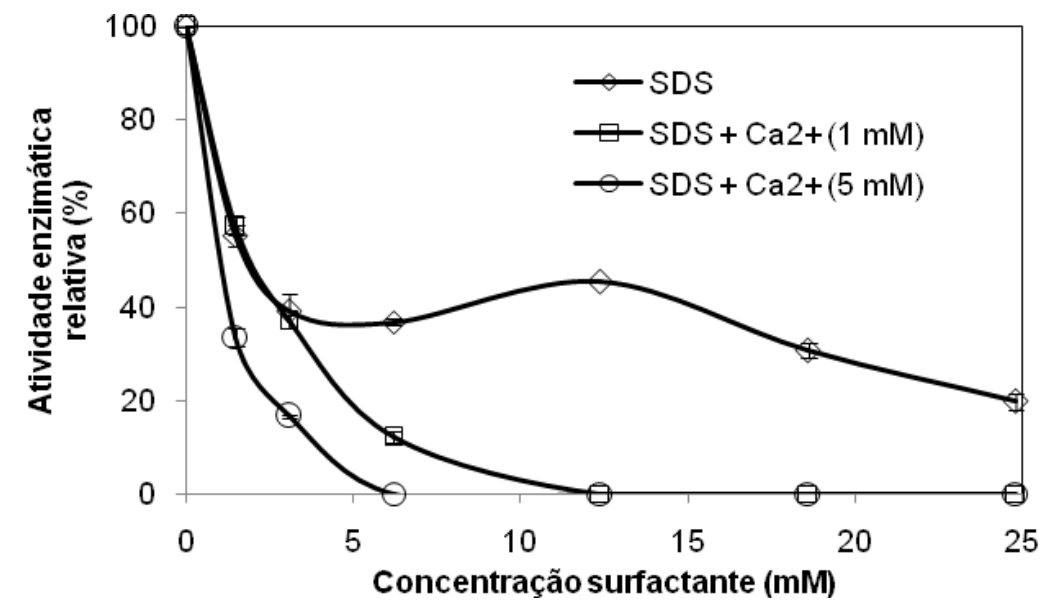

Figura 2: Efeito de diferentes concentrações de SDS com e sem adição de íons cálcio na atividade da lipase de Botryosphaeria ribis EC-01. Cada ponto é uma média de triplicatas \pm SD.

Trabalhos na literatura relatam que o íon $\mathrm{Ca}^{2+}$ pode, em alguns casos, elevar a atividade de lipases em meio contendo surfactantes e contribuir para aumentar a atividade e estabilidade da enzima durante o processo reacional (Diaz et al. 2007; Polizelli et al. 2008; Mendes et al. 2012). 


\section{SIMPÓSIO DE BIOQUÍMICA E BIOTECNOLOGIA}

05 a 07 de agosto de 2015, Londrina - PR

\section{VSIMBBTEC}

Londrina 2015

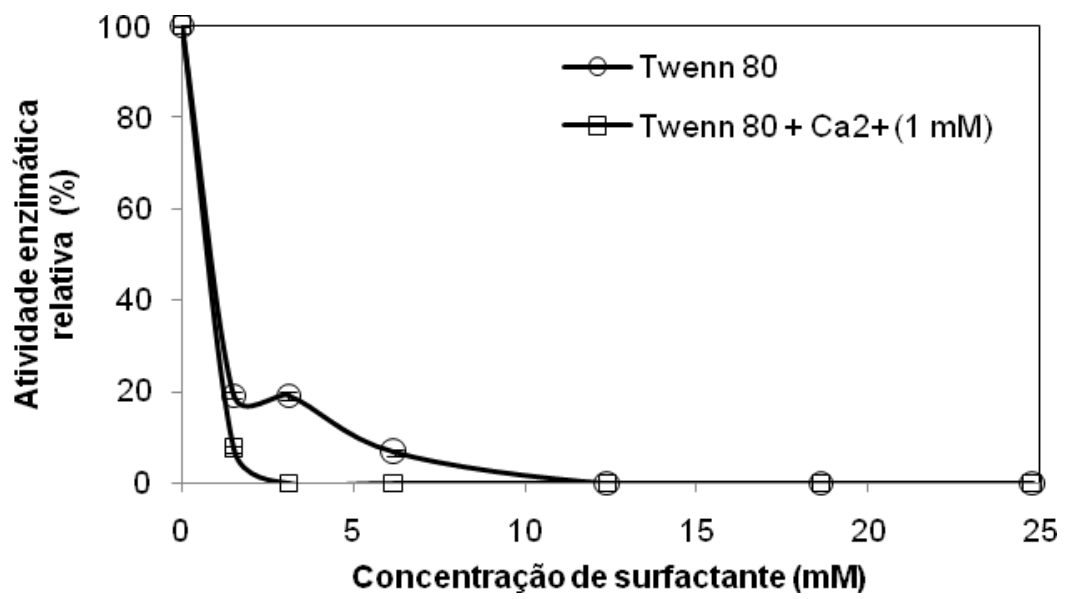

Figura 3: Efeito de diferentes concentrações de Tween 80 com e sem adição de íons cálcio na atividade da lipase de Botryosphaeriaribis EC-01. Cada ponto é uma média de triplicatas \pm SD.

\section{CONCLUSÕES}

Os resultados demonstraram que concentrações crescentes dos surfactantes Tween 80 e CTAB apresentaram efeito negativo na atividade da lipase de $B$. ribis EC-01, independentemente da adição de $\mathrm{Ca}^{2+}$. Entretanto na presençade SDS, a lipase foi mais ativa tendo mantido cerca de $40 \%$ de sua atividade, em altas concentrações, sem a presença de $\mathrm{Ca}^{2+}$ no meio reacional. Estes resultados são promissores para estudos futuros envolvendo esta lipase em formulações de detergentes já que este surfactante é amplamente utilizado.

\section{REFERÊNCIAS}

BARROS, M., FLEURI, F.F., MACEDO, G.G. Seed Lipases: sources, applications and properties - a review. Brazilian Journal of Chemical Engineering, v. 27 p. 15-29, 2010.

JAEGER, K.E.; EGGERT, T. Lipases for biotechnology. Current Opinion in Biotechnology, v. 13, p.390-397,2002.

MENDES, A. A., OLIVEIRA, P. C., DE CASTRO, H. F. Properties and biotechnological applications pancreatic lipase. Journal of Molecular Catalysis B: Enzymatic, v. 78, p. 119-134, 2012.

MESSIAS, J.M.; COSTA, B.Z.; LIMA, V.M.G; DEKKER, R.F.H.; REZENDE, M.I.; KRIEGER, N.; BARBOSA, A.M. 2009. Screening Botryosphaeria species for lipases: Production of lipase by Botryosphaeria ribis EC-01 grown on soybean oil and other carbon sources. Enzyme and. Microbial Technology, v. 45, p. 426-431.

OTERO, C.., FERNANDEZ-PÉREZA, M., HERMOSOB, J.A., RIPOLL, M.M. Activation in the family of Candida rugosaiso lipases by polyethylene glycol. Journal of Molecular Catalysis B: Enzymatic, v. 32 p. 225-229, 2005.

Polizelli, P.P., Tiera, M.J., Bonilla-Rodriguez, G.O. Effect of Surfactants and Polyethylene Glycol on the Activity and Stability of a Lipase from Oilseeds of Pachira aquatica. Journal American of Chemical Society , v. 85, p. 749753, 2008.

REIS, P., HOLMBERG, K., WATZKE, H., LESER, M.E., MILLER, R. Lipases at interfaces: A review. Advances in Colloid and interface Science, v. 147-148, p.237-250, 2009.

Universidade Estadual de Londrina-Rodovia Celso Garcia Cid, Pr 445, Km 380 - Campus Universitário Caixa Postal 10.011 CEP 86057-970Centro de Ciências Exatas - Departamento de Bioquímica e BiotecnologiaFone +55 (43) 3371.4270 - biq@ uel.br 